\title{
ANÁLISE DA RELAÇÃO ENTRE DÉFICIT PÚBLICO E INFLAÇÃO NA ECONOMIA BRASILEIRA A PARTIR DAA DÉCADA DE 1980
}

\author{
ANALYSIS OF THE RELATIONSHIP BETWEEN \\ PUBLIC DEBT AND INFLATION RATES IN THE \\ BRAZILIAN ECONOMY FROM THE DECADE OF 1980
}

Recebido 27/07/2012

Aceito $30 / 07 / 2012$

Camila Albornoz Brufao ${ }^{1}$ Reisoli Bender Filho ${ }^{2}$

\section{RESUMO}

O presente trabalho tem por objetivo analisar a trajetória da dívida pública e da taxa de inflação na economia brasileira a partir da década de 1980, bem como verificar a existência de uma relação de causalidade entre as variáveis. Para verificar a existência dessa relação, foram realizados testes de causalidade de Granger. Para tanto, foram considerados diferentes períodos. No primeiro, foi analisado o período em sua totalidade (1981-2009); no segundo, o período anterior ao plano Real (1981-1994); e, no terceiro, o período posterior ao plano Real (1995-2009). Os resultados obtidos diferem de período para período. Para o período como um todo, a relação encontrada indica que a inflação apresentou relação de precedência ao déficit público. Para o período anterior ao Plano Real, não foi encontrada qualquer relação causal entre as variáveis, enquanto que, para o período posterior ao plano, a relação de causalidade encontrada foi no sentido do déficit público para a inflação.

Palavras-chave: Déficit público; Inflação; Causalidade de Granger

\footnotetext{
${ }^{1}$ Graduada em Economia pelo Centro Universitário Franciscano, Mestranda no Programa de Pós Graduação de Economia e Desenvolvimento (PPGE\&D) da Universidade Federal de Santa Maria (UFSM). E-mail: camilabrufao@hotmail.com

${ }^{2}$ Doutor em Economia Aplicada pela Universidade Federal de Viçosa (UFV), professor adjunto do curso de Administração da Universidade Federal de Santa Maria (UFSM). E-mail: reisolibender@yahoo.com.br
} 


\section{ABSTRACT}

The study aimed to analyze the trajectory of public debt and inflation rates in the Brazilian economy from the 1980s, as well as verify the existence of a causal relationship between variables. To verify the existence of the relationship Tests of Granger causality were conducted. For this, were considered different periods. At first, it was analyzed the entire period (1981-2009), the second, the period before the Real plan (1981-1994) and third, the period after the peal Plan (1995-2009). The results obtained differ from period to period. For the period as a whole, the relationship found indicates that inflation presented to the precedence relation budget deficit. For the period before the Real plan, there was no causal relationship between variables, while for the period after the plan, the causal relationship was found in the sense that the budget deficit to inflation.

Keywords: Public debt; Inflation; Granger causality

\section{INTRODUÇÃO}

A interrupção, na década de 1980, de um longo período de crescimento que caracterizou o Brasil na década de 1970 é resultado de um amplo conjunto de fatores, entre os quais, o crescimento insustentável da dívida externa, o fracasso dos programas heterodoxos de combate à inflação, a imobilização gerada por um excessivo protecionismo à indústria nacional, e o esgotamento de um modelo de desenvolvimento. Esses aspectos baseavamse, fundamentalmente, na intervenção generalizada do Estado na economia, a qual diminuiu sensivelmente a sua capacidade de investimento.

No entanto, é no seu aspecto financeiro que a crise se tornou mais aguda, levando a economia a um processo inflacionário jamais registrado, o qual provocou a queda nos níveis de poupança do setor público, criando um ambiente de incertezas, dificultando a retomada dos investimentos e provocando a ampliação dos desequilíbrios sociais, conforme destacaram Fernandes e Pais (1992).

Já a década de 1990 foi marcada não só pela recessão em seu início, fruto dos efeitos dos fracassados planos de controle inflacionário, mas também por uma profunda reestruturação produtiva. Essa reestruturação, designada por alguns autores como modernização conservadora ${ }^{1}$, ocorreu como desdobramento do esgotamento do modelo de substituição de importações e foi influenciada principalmente pelos pressupostos do Consenso de Washington ${ }^{2}$, a exemplo do que ocorria nos demais países em toda América Latina. Processo este que provocou aceleração no processo de privatização de empresas estatais, abertura da economia e desregulamentação dos mercados.

No entanto, apesar dos avanços, o principal problema de ordem econômica não havia sido solucionado, ao passo que os preços cresciam descontroladamente, acentuando cada vez mais a instabilidade econômica. Dessa forma, em 1994, foi implementado o plano Real, o qual defendia que era o excessivo gasto público o maior responsável pela manutenção das taxas de inflação em patamares elevados (CASTRO, 2005).

Esse plano conseguiu alcançar sucesso no que se refere à estabilização do nível de preços, entretanto outros problemas permaneceram, e alguns até se agravaram. A confiança de que, com a estabilização, o país iria retomar a trajetória estável de crescimento não se verificou,

\footnotetext{
1 Trata-se de uma expressão cunhada pelo historiador Barrington Moore para qualificar o modelo autoritário de desenvolvimento do capitalismo retardatário do século XIX (LACERDA, 2005).

2 Nome dado à reunião ocorrida em novembro de 1989, em Washington, nos Estados Unidos, com integrantes do governo norte-americano e dos organismos financeiros internacionais ali sediados especializados em assuntos latino-americanos (FMI, BM, e BIRD), junto a economistas latino-americanos, com o objetivo de avaliar as reformas econômicas empreendidas nos países da região para enfrentarem a crise.
} 
ao passo que os juros elevados e o câmbio sobrevalorizado aumentavam a vulnerabilidade externa, restringindo o crescimento econômico e agravando a situação das contas públicas.

No período pós-Real, a inflação manteve-se em níveis baixos, em meio a um contexto econômico mais estável, mas a equação básica do crescimento não foi solucionada. Entre os anos de 2000 e 2003, a relação dívida/PIB apresentou uma trajetória ascendente, chegando a 52,14\% no último ano. A partir de então, começou a ser reduzida, alcançando, em 2009, 41,35\% do PIB, o seu menor valor. A inflação, por outro lado, não apresentou uma trajetória claramente definida durante esse período: com oscilações, chegando em 2002 ao seu valor máximo de 27,66\% ao ano, para apresentar deflação em -1,43\% ao ano, em 2009 (IPEADATA, 2010).

Nitidamente, podem ser visualizados contextos opostos. No período anterior ao plano Real, a taxa de inflação apresentou trajetória ascendente, principalmente entre os anos de 1981 e 1986, enquanto o déficit público declinava. Durante o período pós-estabilização, os resultados foram contrários, enquanto o processo inflacionário apresentava trajetória decrescente, o endividamento público apresentava constante crescimento.

A partir dessas considerações, a relação de causa e efeito entre o déficit público e a taxa de inflação tornou-se uma questão em aberto, uma vez que a relação entre ambos não permite inferir posições definitivas. Assim, o presente trabalho tem por objetivo fazer uma análise da trajetória do déficit público e do processo inflacionário na economia brasileira a partir da década de 1980, bem como verificar a existência ou não de uma relação causal entre essas variáveis macroeconômicas.

A análise proposta procurou contribuir para o entendimento, ainda que de forma parcial, dos efeitos do processo de estabilização sobre a condução da política econômica brasileira, uma vez que o processo de estabilização, como foi executado, enfrentou diversas críticas e discordâncias.

Além desta breve introdução, o trabalho está organizado em mais quatro seções. A seção dois discute a trajetória da inflação e do déficit público na economia brasileira a partir da década de 1980. A seção três apresenta a metodologia utilizada para atingir o objetivo proposto. A seção quatro consta da análise e discussão dos resultados. A seção cinco expõe as conclusões acerca do tema abordado.

\section{A INFLAÇÃO E O DÉFICIT PÚBLICO NA ECONOMIA BRASILEIRA}

O comportamento tanto da inflação quanto do déficit público tem sido tema de recorrentes debates e discordâncias na literatura econômica especializada, sobretudo nas últimas três décadas. Contudo, a relação entre esses dois agregados pode ser dividida em dois períodos distintos. O primeiro compreende dos anos 1980 até o ano de 1994, e o segundo inicia com a introdução do plano Real e se estende até o período mais recente.

\subsection{As finanças públicas e o regime de alta inflação: de 1981 a 1994}

A década de 1980 e a primeira metade da década de 1990 foram períodos extremamente delicados quando se analisam as contas públicas e o aspiral inflacionário, uma vez que o déficit público apresentou aumentos expressivos ao mesmo tempo em que a inflação alcançou níveis até então não verificados.

Nesse processo, os efeitos da inflação foram amplos. Entretanto, o aspecto mais relevante refere-se à sua relação com o déficit público, sendo que esses dois agregados podem 
se relacionar de duas formas, conforme Gobatto e Castilho (2006). A primeira ocorre quando o governo gera um déficit que precisa de financiamento, e os agentes não estão dispostos a comprar uma parcela da dívida por meio da compra de títulos públicos. Com isso, o governo é obrigado a emitir moeda, aumentando a base monetária e elevando, por conseguinte, a taxa de inflação. A segunda ocorre quando a inflação afeta o déficit público por meio da corrosão do valor da arrecadação fiscal dos impostos, ou seja, pela defasagem entre a sua geração e o seu recolhimento. Processo que ficou conhecido na economia brasileira como efeito-Tanzi.

Diante desse cenário adverso, a década de 1980 pode ser considerada um dos piores períodos para a história econômica do Brasil. Após o período de milagre econômico (1968-1973), em que a economia cresceu a taxas superiores a $10 \%$ ao ano, o país entrou em crise. A partir de 1973, a taxa de inflação começou a se elevar, chegando, em 1980, ao patamar próximo dos $100 \%$ ao ano, conforme Baer (2003).

Nos primeiros anos da referida década, a situação se agravou e, em 1983, a taxa chegou a $211 \%$, subindo, em 1984 , para mais de $220 \%$ e atingindo quase $300 \%$ no início de 1986 . Nesse período, a situação econômica tornou-se insustentável, e, dado o diagnóstico de inflação inercial ${ }^{3}$, o choque heterodoxo tornou-se uma alternativa inevitável. Com esse contexto, em 1986, instaurou-se o primeiro de uma série de planos heterodoxos de combate à inflação: o plano Cruzado, o qual foi seguido pelos planos Bresser, Verão, e Collor I e II, todos igualmente fracassados em seu objetivo.

A sequência de fracassos dos planos de estabilização, associada às constantes mudanças nas regras da política de estabilização, fez com que os resultados alcançados pelo país fossem inexpressivos em termos de crescimento, resultando com que a economia entrasse em recessão, com alto grau de desemprego, elevados níveis de endividamento, déficit e inflação (LAZANA e LOPEZ, 2009).

Consubstanciadamente, na trajetória da dívida pública brasileira no decorrer do período de elevada inflação, podem-se verificar duas tendências, conforme se observa na Figura 1. A primeira, ocorrida na primeira metade da década de 1980, caracterizou-se pela elevação da relação dívida/PIB, em um contexto de forte déficit fiscal e estagnação econômica. Já a segunda, ocorrida após meados da década de 1980, evidenciou um cenário de crescimento do PIB, estando o mesmo associado a um déficit similar ao da primeira metade da década, isso resultou uma queda na relação dívida/PIB.

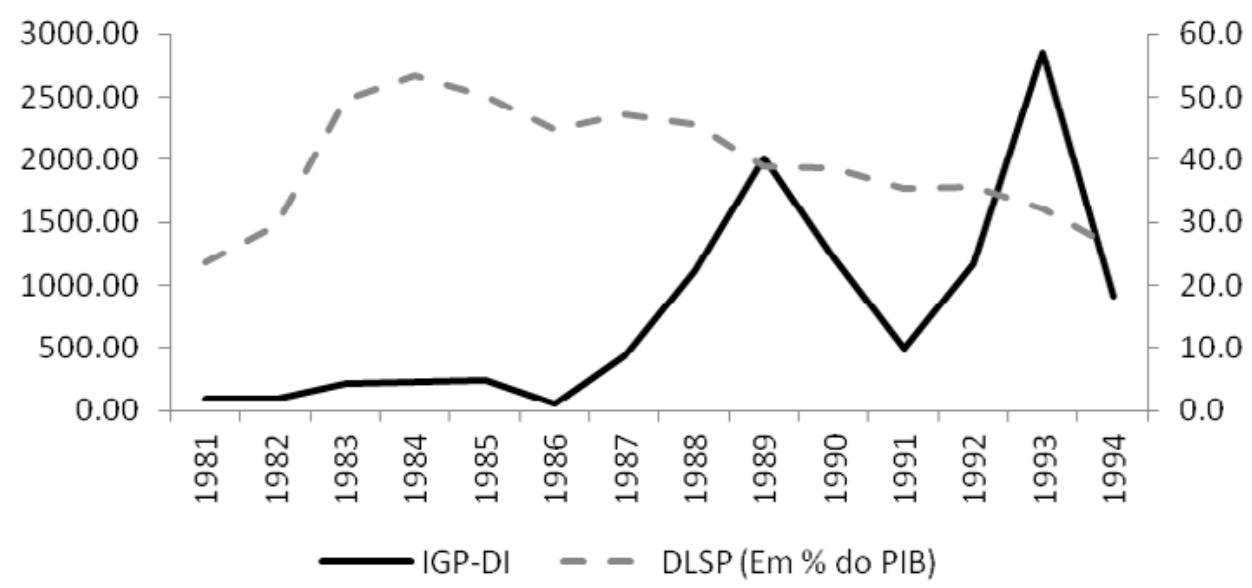

Figura 1 - Variação mensal da inflação brasileira, medida pelo IGP-DI e DLSP em \% do PIB, entre 1981 e 1994. Fonte: IPEADATA, 2010.

${ }^{3} \mathrm{~A}$ ideia básica da inflação inercial é que, a partir de um determinado momento, a inflação adquire certa autonomia, isto é, assume um comportamento inercial, dado que a inflação do período passado determina a inflação atual, que determinará, por sua vez, a inflação futura, e assim por diante. Essa inércia resulta dos mecanismos de indexação (correção monetária dos preços, salários, câmbio e ativos financeiros), que tendem a propagar a inflação passada para o futuro. Na ausência de choques, a inflação permaneceria no patamar vigente, ou seja, ter-se-ia a aderência do conceito a uma taxa de inflação estável (BAER, 2003). 
A combinação de fatores como a crise externa, a falta de empenho das autoridades em combater o déficit público e a fragilidade política do governo, conforme discutido por Giambiagi e Além (2000), gerou uma significativa deterioração da situação fiscal entre os anos de 1984 e 1989, tendo o déficit operacional passado de $3,2 \%$ do PIB durante $1983 / 1984$ para 5,9\% do PIB em 1988/1989. A relação dívida/PIB, por outro lado, passou de 53,4\% em 1984 para 38,9\% em 1989, trajetória que continuou nos primeiros anos da década de 1990 (IPEADATA, 2010).

Essa queda da relação dívida/PIB pode ser atribuída, segundo Giambiagi (1996), à combinação de uma elevada senhoriagem com a corrosão da dívida pública associada à subindexação da dívida interna e da taxa de câmbio desvalorizada. Já entre 1990 e 1994, o fator predominante da queda do endividamento total, de $39 \%$ do PIB para menos de $25 \%$ do PIB, foi decorrente da senhoriagem ter sido muito superior às necessidades de financiamento do setor público (NFSP).

Em síntese, pode-se constatar um processo divergente entre o endividamento público e a taxa de inflação na economia brasileira, nos quinze anos que se estenderam desde o início dos anos de 1980 até meados da década seguinte.

\subsection{As finanças públicas e a fase de estabilização: de 1995 a 2009}

Entre os anos de 1993 e 1994, argumentava-se que a relação entre inflação e política fiscal no Brasil seria diferente da maioria dos países de inflação elevada, por dois motivos, de acordo com Giambiagi e Além (2000). O primeiro discutia que as características do sistema tributário brasileiro estariam protegendo a receita da incidência do efeito-Tanzi ${ }^{4}$, já que as unidades arrecadadoras reagiriam à elevada inflação, diminuindo o intervalo de recolhimento dos impostos para o mínimo tecnicamente possível e expressando o valor a ser cobrado dos contribuintes não mais na moeda nacional, e sim em unidades de referência, cujo valor se modificava de acordo com a variação da inflação.

O segundo motivo centrava-se no fato de que muito mais importante que a perda do valor real dos tributos seria a ajuda prestada pela inflação ao governo para reduzir o valor real do gasto em relação aos valores comprometidos no orçamento, ou seja, mais importante do que o efeito-Tanzi era o efeito-Bacha, o qual enfatizava que a postergação da liberação de uma verba provocava uma perda real no valor liberado. Logo, com a despesa estabelecida em termos nominais e a receita indexada, essa técnica de administração do gasto público revelava-se extremamente eficaz para combinar a evolução da despesa.

Estes motivos permitem, em grande medida, entender a redução das necessidades de financiamento do setor público no conceito operacional - observada no início da década de 1990 - e, ao mesmo tempo, explicar a continuidade e manutenção das altas taxas de inflação da época. Além disso, essas taxas serviam como justificativa para a necessidade de novas medidas fiscais de caráter contencionista.

Contudo, em 1994, o plano Real conseguiu atingir o seu principal objetivo, a taxa de inflação foi substancialmente reduzida e manteve-se controlada durante os anos seguintes. Porém, outros problemas, como a valorização da taxa de câmbio e a taxa de juros elevada, acentuaramse no período pós-Plano. De tal modo que esse conjunto de políticas gerou consequências tanto na dívida externa como na dívida interna.

De acordo com Gobbato e Castilho (2006), a taxa de câmbio valorizada gerou a necessidade

${ }^{4}$ Definido como a relação direta que há entre a inflação e o tamanho do déficit. Quanto maior a inflação, maior será o déficit, devido à queda no valor real da receita. Essa queda se dá pela defasagem de tempo entre o fato gerador dos tributos e o seu efetivo recolhimento, o que, em caso de aumento dos preços, implica uma corrosão do valor real correspondente. Assim, a perda de valor da receita, em termos de moeda constante, é uma função direta do prazo de recolhimento dos impostos e da taxa de inflação (GIAMBIAGI, ALÉM, 2000). 
de as empresas privadas terem que cobrir suas necessidades financeiras com recursos captados no exterior, aumentando, com isso, a dívida externa. Enquanto isso, o aumento da dívida interna, por sua vez, esteve ligado à manutenção de taxa de juros elevadas, decorrente do rígido ajuste fiscal do setor público, o qual foi composto do corte de gastos e do aumento dos impostos.

Nesse contexto, conforme Mendonça (2004), a controvérsia a respeito da condução da política econômica no Brasil em relação aos possíveis efeitos para o equilíbrio fiscal permanecia. Ao passo que, de um lado, havia o argumento de que uma política monetária concentrada no combate à inflação evitava a manifestação do viés inflacionário, disciplinando os gastos governamentais, o que, por sua vez, contribuía para o alcance do equilíbrio fiscal. De outro lado, a manutenção de uma elevada taxa de juros como principal instrumento de combate à inflação acarretaria um aumento no pagamento de juros reais, contribuindo para uma maior necessidade de financiamento do setor público.

Destarte, no período seguinte à estabilização dos preços, a relação dívida/PIB passou a apresentar uma tendência de crescimento. $O$ elevado déficit público, combinado com a redução do imposto inflacionário como fonte de financiamento, gerou um aumento da dívida líquida do setor público (DLSP), a qual passou de cerca de 26\% em 1994 para 38\% do PIB em 1998 (IPEADATA, 2010).

No final da década, por sua vez, a mudança no regime cambial associada ao aumento do déficit público e à estagnação da economia trouxeram consigo um novo aumento na relação dívida/PIB. Como reflexo, o endividamento elevou-se de 38,1\% em 1998 para 42,6\% em 1999, como pode ser observado na Figura 2. Nessa trajetória de crescimento, deve-se salientar a importância do efeito gerado pela desvalorização do câmbio sobre a soma de dívida interna indexada ao câmbio mais a dívida externa, de $13,8 \%$ do PIB, quando o regime cambial passou a ser flutuante.

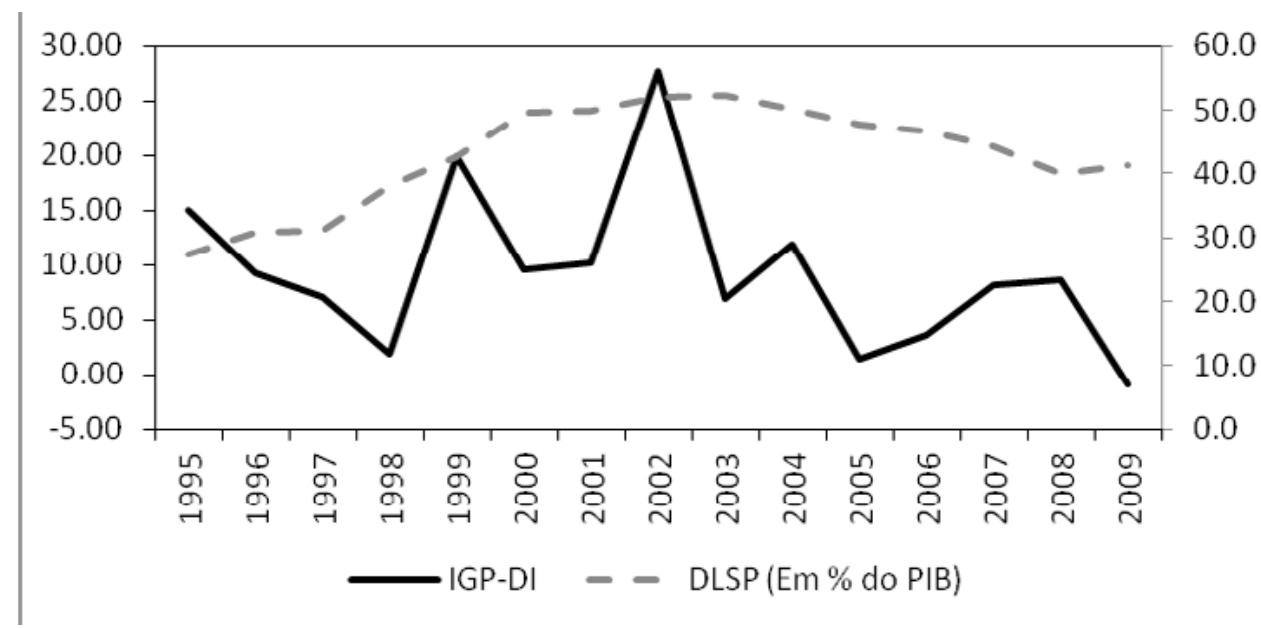

Figura 2 - Variação mensal da inflação brasileira medida pelo IGP-DI e DLSP em \% do PIB, entre 1995 e 2009. Fonte: IPEADATA, 2010.

No que tange o nível de preços, entre os anos de 2000 e 2002, a taxa de inflação apresentou um aumento significativo, passando de $9,8 \%$ para $26,4 \%$ ao ano. Porém, a partir de 2003, o nível de preços apresentou variações, mas com tendência de queda, chegando, em 2009, a apresentar deflação de -1,43\% (IPEADATA, 2010). No mesmo período, a dívida apresentou comportamento praticamente estável; contudo, em 2009, o endividamento público apresentou um aumento significativo, atingindo o seu maior valor da década, aproximadamente $41,35 \%$ do PIB.

A mudança da trajetória da divida verificada nesse período se justifica pela política fiscal 
expansionista realizada pelo governo - por meio da diminuição da arrecadação tributária e do aumento dos seus gastos - , com o objetivo de evitar uma maior retração da atividade econômica e consequentemente da capacidade de crescimento do país, decorrente da crise financeira internacional iniciada em 2007. Além disso, o comportamento de outras variáveis econômicas, como a taxa de câmbio que incide diretamente sobre o estoque da dívida e o aumento da taxa de juros, também interferiram nessa mudança de trajetória, como apontado por Pimentel (2009).

Em suma, uma análise conjunta das variáveis permite observar que, entre os anos de 1995 e 2009, estas apresentaram trajetórias distintas. Sendo que, entre 1995 e o começo da década de 2000, as trajetórias da inflação e do endividamento público foram opostas. O nível de preços apresentou uma tendência de queda - embora tenha apresentado elevação entre 1998 e 1999 -, enquanto a relação dívida/PIB apresentou continua elevação. Já entre 2000 e 2002, a inflação apresentou um aumento significativo, passando a decrescer a partir de 2003 e chegando à deflação em 2009, enquanto o déficit público manteve-se relativamente estável entre $2000 \mathrm{e}$ 2008, elevando-se somente a partir de 2009.

\section{METODOLOGIA}

\subsection{Modelo e hipóteses}

Tendo em vista a problemática discutida, de examinar a relação entre a inflação e déficit público na economia brasileira, desenvolveu-se a metodologia do estudo, a qual parte da modelagem de Granger (1969), que tem como objetivo verificar a existência ou não de uma relação causal (de precedência) entre um par ou um conjunto de variáveis.

Para tanto, a primeira etapa à aplicação do teste de causalidade de Granger passa pela realização dos testes de estacionariedade das séries, cujo objetivo é identificar as caracteristícas das variáveis econômicas utilizadas. Para esse objetivo, foi aplicado o teste de Dickey-Fuller aumentado (ADF).

O teste ADF permite verificar a presença ou ausência de raiz unitária nas séries, sendo conduzido por meio do aumento das equações precedentes pelo acréscimo dos valores defasados da variável dependente $\Delta Y_{t^{\prime}}$ e consistindo em regredir à seguinte expressão:

$$
\Delta Y_{t}=\beta_{1}+\beta_{2} t+\delta Y_{t-1}+\sum_{i=1}^{m} \alpha_{i} \Delta Y_{t-1}+\varepsilon_{t}
$$

em que e $e_{t}$ é um termo de erro de ruído branco puro, e $\Delta Y_{t-1}=\left(Y_{t-1}-Y_{t-2}\right), \Delta Y_{t-2}=\left(Y_{t-2}-Y_{t-3}\right)$ são os termos de diferenças defasadas.

O número de termos de diferenças defasadas a ser incluído é, muitas vezes, determinado empiricamente, sendo que a ideia é incluir um numero de termos suficiente para que o termo de erro em (1) não apresente correlação serial (GUJARATI, 2006). Com base nesse aspecto, o teste tem como hipóteses:

$H_{0}: \rho=0$, presença de raiz unitária (a série é não estacionária)

$H_{a}: \rho<0$, ausência de raiz unitária

Segundo Bueno (2008), o objetivo do teste é estimar um modelo com variáveis autorregressivas. Sendo essa a forma de corrigir o desvio do valor correto da estatística, ou seja, intuitivamente trata-se de encontrar os desvios de $Y_{t}$ em relação à sua média, para deslocar a distribuição de a em direção à zero, caso a hipótese nula seja verdadeira.

Verificada a estacionariedade das séries, a etapa seguinte consistiu na aplicação do teste 
de causalidade de Granger. Esse teste estabelece que se $X$ causa $Y$ no sentido de Granger, então variações em $X$ deveriam preceder variações em $Y$. Em termos formais, pode-se dizer que a variável $Y$ é causada por $X$ no sentido de Granger se os coeficientes das variáveis defasadas de $X$ forem diferentes de zero. Vasconcellos e Alves (2000) complementam que $Y$ Granger causa $X$ se o valor de $X$ em $t$ pode ser predito com maior precisão, sendo considerados valores passados de $Y$, além dos valores passados de $X$.

A causalidade pode ocorrer nas duas direções, de $Y$ para $X$ e de $X$ para $Y$. Porém, quando a causalidade ocorre em uma direção, como, por exemplo, de $X$ para $Y$, não implica que $Y$ é o efeito ou resultado de $X$, conforme salientam Pindick e Rubinfeld (2004). Para Bueno (2008), a questão fundamental é saber se o escalar $X$ ajuda a prever o escalar $Y$. Se isso não acontece, então se diz que $X$ não Granger-causa $Y$. A forma funcional do teste é expressa por meio da estimativa das seguintes equações:

$$
\begin{gathered}
Y_{t}=\alpha_{0}+\alpha_{1} Y_{t-1}+\ldots+\alpha_{k} Y_{t-k}+\beta_{1} X_{t-1}+\ldots+\beta_{k} X_{t-k} \text { (2) } \\
X_{t}=\alpha_{0}+\alpha_{1} X_{t-1}+\ldots+\alpha_{k} X_{t-k}+\beta_{1} Y_{t-1}+\ldots+\beta_{k} Y_{t-k} \text { (3) }
\end{gathered}
$$

O teste de causalidade de Granger tem como hipóteses:

$H_{0}: \beta_{1}=\ldots=\beta_{K}=0$, para cada uma das equações.

$H_{1}:$ caso contrário

Caso a hipótese nula não seja rejeitada, conclui-se que $X$ não Granger causa $Y$ em (2), e $Y$ não Granger causa $X$ em (3). Por outro lado, caso a hipótese nula seja rejeitada, há uma relação de precendência entre as variáveis, considerando a equação ou as equações particularmente analisadas. Empiricamente, estimaram-se as seguintes equações:

$$
\begin{aligned}
& D P_{t}=\alpha_{0}+\alpha_{1} D P_{t-1}+\ldots+\alpha_{k} D P_{t-k}+\beta_{1} I N F_{t-1}+\ldots+\beta_{k} I N F_{t-k} \text { (4) } \\
& I N F_{t}=\alpha_{0}+\alpha_{1} I N F_{t-1}+\ldots+\alpha_{k} I N F_{t-k}+\beta_{1} D P_{t-1}+\ldots+\beta_{k} D P_{t-k}(5)
\end{aligned}
$$

sendo $D P$ a dívida pública e $I N F$ a taxa de inflação. Como hipóteses nulas $\left(H_{0}\right)$, têm-se que: em (4), $I N F$ não Granger causa $D P$; e, em (5), $D P$ não Granger causa $I N F$.

Destaca-se que foram estimados três modelos, o primeiro compreendeu a integralidade do período analisado, correspondente aos anos de 1981 e 2009 (modelo 1); o segundo incluiu somente o período entre os anos de 1981 e 1994, considerado o período de desequilíbrios e instabilidades econômicas (modelo 2); e o terceiro analisou a referida relação para os anos entre 1995 e 2009, tendo esse período como caracteristíca a estabilidade do nível de preços obtida a partir da implementação do plano Real (modelo 3).

\subsection{Variáveis e dados utilizados}

A respeito das variáveis optou-se por utilizar a taxa de inflação medida pelo Índice Geral de Preços - Disponibilidade Interna (IGP-DI), expressa em variação percentual; e a Dívida Líquida do Setor Público (DLSP) como medida do déficit público, expressa em milhões de reais. Para ambas as variáveis, foram utilizados dados com periodicidade anual, sendo a DLSP deflacionada pelo IGP-DI, com base em 2009. Os dados foram obtidos junto ao banco de dados do Instituto de Pesquisa Econômica Aplicada (IPEADATA), que tem como fonte o Banco Central.

A escolha do período analisado baseou-se em contrastar contextos com características distintas no que tange ao endividamento público e ao processo inflacionário. Dessa forma, o 
teste foi aplicado para o período como um todo (1981-2009) e para dois subperíodos, como segue: anterior ao Plano Real (1981-1994) e pós-Real (1994-2009).

\section{ANÁLISE E DISCUSSÃO DOS RESULTADOS}

A primeira etapa para a aplicação do teste de causalidade de Granger consistiu na realização do teste de Dickey-Fuller Aumentado para verificar a estacionariedade das séries econômicas analisadas. Os resultados do teste ADF podem ser observados na Tabela 1, para ambas as variáveis, inflação e dívida líquida do setor público.

Tabela 1 - Resultados do teste de estacionariedade ADF para as variáveis inflação e dívida pública, para o período entre 1981 e 2009.

\begin{tabular}{|c|c|c|c|c|c|c|}
\hline \multicolumn{7}{|c|}{ Taxa de inflação - IGP-DI } \\
\hline \multirow{2}{*}{$\begin{array}{c}\text { Nível de } \\
\text { Significância }\end{array}$} & \multicolumn{2}{|c|}{ Com intercepto } & \multicolumn{2}{|c|}{$\begin{array}{l}\text { Com intercepto } \\
\text { e tendência }\end{array}$} & \multicolumn{2}{|c|}{ Sem intercepto e tendência } \\
\hline & Nível & Diferença & Nível & Diferença & Nível & Diferença \\
\hline $10 \%$ & -2.629906 & -2.629906 & -3.229230 & -3.233456 & -1.609329 & -1.609329 \\
\hline $5 \%$ & -2.981038 & -2.981038 & -3.587527 & -3.595026 & -1.954414 & -1.954414 \\
\hline $1 \%$ & -3.711457 & -3.711457 & -4.339330 & -4.356068 & -2.656915 & -2.656915 \\
\hline Estatística ADF & -1.296012 & -6.673477 & -3.108456 & -6.639902 & -1.091291 & -6.814806 \\
\hline \multicolumn{7}{|c|}{ Dívida pública - DLSP } \\
\hline $10 \%$ & -2.625121 & -2.627420 & -3.225334 & -3.229230 & -1.609798 & -1.609329 \\
\hline $5 \%$ & -2.971853 & -2.976263 & -3.580623 & -3.587527 & -1.953381 & -1.954414 \\
\hline $1 \%$ & -3.689194 & -3.699871 & -4.323979 & -4.339330 & -2.650145 & -2.656915 \\
\hline Estatística ADF & -0.741462 & -3.883740 & -1.658697 & -3.698052 & 1.290802 & -3.628638 \\
\hline
\end{tabular}

Fonte: Resultado da pesquisa, elaborado pelos autores.

Como pode ser observado, tanto a variável inflação como a dívida pública são não estacionárias (apresentaram raiz unitária) em nível para todos os modelos adotados (com intercepto, com intercepto e tendência, sem intercepto e sem tendência). Por outro lado, quando estimados em primeira diferença, a variável taxa de inflação mostrou-se ser estacionária ao nível de $1 \%$ de significância para todos os modelos adotados. O déficit público, por sua vez, apresentou, em primeira diferença, estacionariedade ao nível de significância de $1 \%$ nos modelos com intercepto e sem intercepto e tendência; e estacionariedade ao nível de significância de $5 \%$ no modelo com intercepto e tendência. Deste modo, constata-se que as séries são estacionárias em primeira diferença.

Após a identificação das características das séries, realizou-se o teste de causalidade (ou precedência temporal) de Granger, com as variáveis em primeira diferença e com a utilização de dois lags. Os resultados do teste encontram-se na Tabela 2, sendo que estes estão divididos em três blocos: o primeiro refere-se à estimação do modelo para o período como um todo (19812009), o segundo e terceiro referem-se às estimações dos subperíodos 1981-1994 e 1995-2009, respectivamente.

Ao analisar o período como um todo (1981-2009), não se pode rejeitar, ao nível de $10 \%$ de significância, a hipótese nula de que a dívida pública não causa, no sentido de Granger, a inflação; enquanto foi refutada a hipótese nula de que a inflação não causa, no sentido de Granger, 
o déficit público. Logo, para o período entre 1981 e 2009, movimentos inflacionários mostraram uma relação de precedência às variações na trajetória do endividamento público brasileiro.

A respeito desse resultado, o que se verificou na economia brasileira foi uma grande oscilação da taxa de inflação durante o período anterior ao plano Real, chegando ao seu pico (2708\% ao ano) em 1993, embora, ao longo do período, a sua tendência seja de queda, enquanto o déficit público apresenta uma trajetória ascendente. Já nos anos mais recentes, tem-se um cenário distinto, com a inflação mantida em níveis baixos e estando mais controlada - salvo alguns anos como os de 2002 e 2008 -, enquanto o endividamento público apresentava mudanças mais expressivas.

Nesse contexto, as evidências, em certa medida, estão de acordo com os resultados obtidos quando se considera que o processo inflacionário brasileiro foi decorrente de um conjunto de fatores, e o endividamento foi consequência deste processo. Contudo, ressalta-se que as elevadas mudanças no decorrer do período, tanto as de ordem econômica quanto as de ordem política, indicam que esse resultado deve ser analisado com certo grau de cautela, quando considerada unicamente sua relação de precedência.

Tabela 2 - Resultados do teste de causalidade de Granger para as variáveis inflação e dívida pública, na economia brasileira.

\begin{tabular}{ccc}
\hline & \multicolumn{1}{c}{ Estatistica F } & Prob. \\
\hline \multicolumn{3}{c}{ Período de 1981 - 2009 (modelo 1) } \\
\hline$D P$ não Granger-causa $I N F$ & 0.92178 & 0.3466 \\
$I N F$ não Granger-causa $D P$ & 2.54141 & 0.1040 \\
\hline \multicolumn{3}{c}{ Período de 1981-1994 (modelo 2) } \\
\hline$D P$ não Granger-causa $I N F$ & 0.00896 & 0.9266 \\
$I N F$ não Granger-causa $D P$ & 0.71361 & 0.4201 \\
\hline \multicolumn{2}{c}{ Período de 1994-2009 (modelo 3) } \\
\hline$D P$ não Granger-causa $I N F$ & 6.95472 & 0.0178 \\
$I N F$ não Granger-causa $D P$ & 0.04242 & 0.9587 \\
\hline
\end{tabular}

Fonte: Resultado da pesquisa, elaborados pelos autores.

Quando se restringe a análise ao período de 1981-1994 (modelo 2), não podem ser rejeitadas tanto a hipótese nula de que o déficit público não causa inflação no sentido de Granger, quanto a hipótese nula de que a inflação não causa déficit público. Portanto, para esse período, não foi verificada qualquer relação de precedência temporal entre as variáveis econômicas examinadas. Resultado que evidencia a não consensualidade do próprio debate teórico acerca da relação existente entre essas variáveis.

Para esse período, a relação entre a aceleração inflacionária e o endividamento público tem sido discutida sob visões diferenciadas. Uma delas enfatiza que as altas taxas de inflação aumentavam o déficit público por meio do efeito-Tanzi. Enquanto a outra propõe que as altas taxas de inflação contribuíam para a redução do valor real do gasto público, diminuindo, assim, o nível do déficit, o que foi denominado de efeito-Bacha.

A partir dessas proposições, o que se verificou na economia brasileira no período de instabilidade econômica foi à aceleração das taxas de inflação, com oscilação maior no período de 1981 e 1986 e menor variação entre 1988 e 1994. Por outro lado, o endividamento público apresentou 
tendência de queda, o que estaria mais em linha com a proposta discutida pelo efeito-Bacha.

Conforme Garcia (1995), o clima de incerteza gerado pela aceleração inflacionária observada na década de 1980 gerou a tendência do setor privado de atuar de forma defensiva, deixando de priorizar grandes investimentos. Coincidentemente, esse período de aceleração inflacionária veio acompanhado de um aumento da dívida mobiliária federal, em função do aumento da emissão de títulos da dívida pública federal, processo que foi utilizado para cobrir o desequilíbrio financeiro no setor público.

Já para Messenberg (1997), embora a maioria dos analistas apontasse o déficit público e as características dos instrumentos utilizados para o seu financiamento como principais fatores para a instabilidade econômica do período, o aparente consenso se revelou contraditório com as reações provocadas pela adoção do plano Collor no início da década de 1990 . Assim sendo, duas linhas de argumentação passaram a discutir as possíveis ligações da dívida interna com a inflação: enquanto, por um lado, enfatizava-se a excessiva liquidez gerada pelos títulos públicos, por outro, defendia-se a própria magnitude alcançada pelo seu estoque como elo entre os agregados.

Nesse contexto, a primeira argumentação era sustentada pelos monetaristas, os quais enxergavam a taxa de inflação como reflexo da expansão nominal dos agregados monetários. De maneira geral, responsabilizavam, além do próprio déficit público, a condução da política econômica por tal resultado. A segunda alegação era uma revisão do inercialismo, a qual ganhou destaque com a permanência das elevadas taxas de inflação após o fracasso dos planos Collor I e II. Essa visão destacava a não neutralidade da inflação em relação à alocação de portfólio dos agentes e condenava a postura de que, dada a estabilização, aumentariam naturalmente os recursos necessários ao seu financiamento. Sendo que tal financiamento envolvia absorção de poupança privada, geralmente por meio de uma tributação inflacionária, e de poupança externa, provocando, assim, um desequilíbrio na conta de transações correntes (MESSEMBERG, 1997).

Ao analisar estatisticamente o período mais recente, pós-plano Real, entre 1995 e 2009 (modelo 3), rejeita-se a hipótese nula, ao nível de $1 \%$ de significância, de que o déficit público não causa, no sentido de Granger, a inflação. Por outro lado, não pode ser rejeitada a hipótese de que a taxa de inflação não Granger causa déficit público. Assim sendo, nesse período, pode-se inferir que o déficit público apresentou uma precedência temporal à ascensão inflacionária na economia brasileira. Essa evidência corrobora a hipótese proposta pelo presente estudo de que, com o aumento dos gastos públicos, surge a necessidade de financiamento deste, de forma que o governo, ao elevar a base monetária, gera pressão sobre o nível de preços.

Esse resultado segue a linha daqueles encontrados por Triches e Morais (2003), para o período entre 1991 a 1999, e por Mendonça (2004), para o período 1995 a 2003. Os autores encontram indícios de que tanto o déficit público nominal quanto o primário causaram inflação durante o período pós-Real, não sendo verdade o contrário. Esse fato tende a ser consistente com as principais concepções teóricas do déficit público. Na realidade da economia brasileira, o que se verificou foi uma trajetória decrescente da inflação, embora apresentasse sempre taxas positivas, e uma trajetória ascendente do endividamento. Em outras palavras, o aumento do gasto público gera condições para a expansão inflacionária, a qual ocorre por meio do aumento da base monetária necessária para cobrir a ampliação do déficit orçamentário.

Na visão de Corsi (2000), o aumento dos gastos públicos nos anos seguintes à implementação do Real foi causado pela estratégia do governo de combater a inflação com a combinação de valorização da moeda e abertura comercial. Segundo Corsi (2000), a elevação das taxas de juros gerou um endividamento externo em grande medida desnecessário, pois os enormes déficits em conta corrente foram resultado de uma situação criada artificialmente pelo governo, que buscou 
combater a inflação ampliando a oferta interna por meio do incremento das importações e acabou financiando uma larga substituição da produção nacional por produtos importados.

Já autores como Pastore e Pinotti (2000), discutiam que a expansão do endividamento público nos anos precedentes ao plano Real, ainda no período de câmbio administrado, dava-se em função do aumento das Necessidades de Financiamento do Setor Público (NFSP), que era explicada principalmente pela evolução dos gastos primários, que não teriam sido devidamente controlados na primeira fase do plano.

A partir do conjunto de resultados, pode-se sumarizar que, embora a dívida pública e a inflação estivessem, em alguma medida, relacionadas à economia brasileira, essa relação não era unidirecional, muito menos consensual, e ocorreu de forma distinta nos períodos analisados. Nesse sentido, a hipótese de que o aumento no nível de endividamento público tende a elevar as taxas de inflação por meio de uma expansão monetária não pode ser refutada apenas para o período entre 1995 e 2009. Tal resultado sugere que as elevações no gasto público tenderam a gerar efeitos mais efetivos sobre o nível de preços da economia em um contexto de maior estabilidade econômica, como se verificou no contexto econômico recente.

\section{CONCLUSÕES}

$\mathrm{Na}$ trajetória recente da economia brasileira, um assunto que continua sendo tema de debate na literatura econômica especializada consta do trade-off déficit público e inflação. Essa questão é muito mais abrangente que a forma aqui abordada, no entanto objetivou-se examinar o sentido da causalidade (precedência temporal) nessa relação, considerando períodos diferentes, com contextos e políticas econômicas diferenciadas, caso da década de 1980 e do período posterior ao plano Real.

Os resultados do teste de Granger não identificaram a direção de causalidade entre as variáveis constantes do modelo, quando considerado o período entre 1981 e 1994. Já quando restringida a análise ao período entre 1995 e 2009, evidenciou-se que a natureza da precedência ocorreu da dívida pública para a inflação, resultado que é corroborado pela teoria macroeconômica do setor público. Também, o presente estudo não se distanciou de outros sobre a economia brasileira, para períodos semelhantes, porém se utilizou de outras medidas (variáveis) de endividamento, como o de Triches e Morais (2003), Mendonça (2004) e Gobatto e Castilho (2006).

Contudo, convém ressaltar que a análise entre déficit público e inflação na economia brasileira não se restringe unicamente ao entendimento da trajetória de ambos os agregados, mas passa pela compreensão de um conjunto de outras variáveis. Nesse sentido, destaca-se que, no período de instabilidade econômica, a variação dos preços devia-se ao crescente e persistente déficit orçamentário, bem como a um cenário internacional desfavorável; enquanto, no período de estabilidade, o déficit e a inflação estiveram associados à política econômica de juros e de câmbio exercida pela autoridade monetária.

Dessa forma, não considerar esses fatores exógenos pode levar a conclusões equivocadas sobre o real comportamento do endividamento público e da variação do nível de preços na economia brasileira, bem como sobre a relação causal entre estes. Destarte, pesquisas futuras poderão centrar-se na investigação dessa relação, considerando outras variáveis macroeconômicas. 


\section{REFERÊNCIAS}

BAER, Werner. Economia brasileira. 2. ed. rev. atual. e ampl. São Paulo: Nobel, 2003.

BUENO, Rodrigo L. S. Econometría de séries temporais. São Paulo: Cengage Learning, 2008.

CASTRO, Lavinia. B. de. In: Economia brasileira contemporânea: (1945-2004). 10. Reimpressão. Rio de Janeiro: Elsevier, 2005.

CORSI, Francisco L. O Real: um balanço crítico (1994-1998). Acesso em: 27 nov. 2010. Disponível em: http://globalization.sites.uol. com.br/oplano.htm. 2000.

FERNANDES, António J.; PAIS, Cassiano. A Economia Brasileira na Década de 80: consequências da crise da dívida externa, inflação e crise do Estado. Acesso em: 26 mar 2010. Disponível em: http://www2.egi. ua.pt/xxiiaphes/Artigos/a\%20Fernandes\%20 onInflama\%C3\%A7\%C3\%A3o.PDF. 1992.

GIAMBIAGI, Fábio. Elevação e custo da dívida líquida do setor público: 1981/94. Pesquisa e Planejamendo Economico, v.26, n.1, p.67-92. Rio de Janeiro. 1996.

GIAMBIAGI, Fábio; ALÉM, Ana Claudia D. Finanças Públicas: Teoria e Prática no Brasil. 2 ed. Rio de Janeiro: Elsevier, 2000.

GOBBATO, Marcio; CASTILHO, Mara Lucy. Inflação e déficit público no Brasil pós-real - uma aplicação do teste de causalidade de Granger. Revista Faz Ciência, v.8, n. 1, p.105122. 2006.

GUJARATI, Damodar N. Econometría básica. 5 tiragem. Rio de Janeiro: Elsevier, 2006.

IPEADATA. Bancos de dados. Acesso em: 15 ago. 2010. Disponível em: http://www.ipeadata. gov.br/ipeaweb.dll/ipeadata?1137943218.

LAZANA, António Evaristo T.; LOPEZ; Luiz M. Economia brasileira: da estabilização ao crescimento. São Paulo: Atlas, 2009.
MENDONÇA, Helder Ferreira de. Dívida pública e estabilidade de preços no período pósreal: explorando relações empíricas. Estudos Econômicos, São Paulo, v. 34, n. 2, p.345-368, abril-junho, 2004.

PASTORE, Afonso C.; PINOTTI, Maria C. Globalização, Fluxo de Capitais e Regimes Cambiais: reflexões sobre o Brasil. Estudos Econômicos, v. 30, n.1, p.5-26, jan.-mar., 2000.

PIMENTEL, Joyce T. Dívida pública brasileira: Características estruturais e tendências recentes. Nota de conjuntura econômica. N.18. 2009.

PINDICK, Robert S.; RUBINFELD, Daniel L. Econometría: Modelos e previsões. 4 ed. 2 reimpressão. Rio de Janeiro: Elsevier, 2004.

TRICHES, Divanildo; MORAIS, Igor A. C. Déficit público e taxa de inflação: testes de raiz unitária e causalidade para o Brasil - 1991 - 1999. São Paulo: Revista de Economia Política, v. 07, n. 02, p. 267-283, 2003.

VASCONCELLOS, Marco Antonio S.; ALVES, Denisard (Coords). Manual de econometria. São Paulo: Atlas, 2000. 